\title{
Outcome of the Acute Glomerular Injury in Proliferative Lupus Nephritis
}

Avry Chagnac, Bryce A. Kiberd, M. Carmen Fariñas, Samuel Strober, Richard K. Sibley, Richard Hoppe, and Bryan D. Myers Departments of Medicine, Pathology, and Radiotherapy, Stanford University Medical Center, Stanford, California $94305-5114$

\begin{abstract}
Treatment with total lymphoid irradiation (TLI) and corticosteroids markedly reduced activity of systemic lupus erythematosis in 10 patients with diffuse proliferative lupus nephritis (DPLN) complicated by a nephrotic syndrome. Physiologic and morphometric techniques were used serially before, and 12 and 36 mo post-TLI to characterize the course of glomerular injury. Judged by a progressive reduction in the density of glomerular cells and immune deposits, glomerular inflammation subsided. A sustained reduction in the fractional clearance of albumin, IgG and uncharged dextrans of radius $>50 \AA$, pointed to a parallel improvement in glomerular barrier size-selectivity. Corresponding changes in GFR were modest, however. A trend towards higher GFR at 12 mo was associated with a marked increase in the fraction of glomerular tuft area occupied by patent capillary loops as inflammatory changes receded. A late trend toward declining GFR beyond 12 mo was associated with progressive glomerulosclerosis, which affected $57 \%$ of all glomeruli globally by 36 mo post-TLI. Judged by a parallel increase in volume by $59 \%$, remaining, patent glomeruli had undergone a process of adaptive enlargement. We propose that an increasing fraction of glomeruli continues to undergo progressive sclerosis after DPLN has become quiescent, and that the prevailing GFR depends on the extent to which hypertrophied remnant glomeruli can compensate for the ensuing loss of filtration surface area.
\end{abstract}

\section{Introduction}

The advent of increasingly efficacious therapy with immunosuppressive agents has permitted activity of systemic lupus erythematosus (SLE) to be effectively suppressed. When SLE is accompanied by diffuse, proliferative glomerulonephritis (DPLN) ${ }^{1}$ however, up to one-half of patients subjected to intensive immunosuppression have been reported to develop end-stage renal failure within a decade, nevertheless (1-5). One explanation for this unfavorable outcome is that recurrent

Address reprint requests to Dr. Myers, Department of Medicine, S-215 Division of Nephrology, Stanford University Medical Center, Stanford, CA 94305-5114.

Received for publication 1 November 1988 and in revised form 1 May 1989.

1. Abbreviations used in this paper: DPLN, diffuse, proliferative lupus nephritis; GBM, glomerular basement membrane; GFR, glomerular filtration rate; $K_{\mathrm{f}}$, ultrafiltration coefficient; $\omega_{0}$, shunt parameter; $\Delta \mathbf{P}$, glomerular transcapillary hydraulic pressure difference; PAH, paraaminohippuric acid; $r_{0}$, restrictive pore radius; TLI, total lymphoid irradiation.

J. Clin. Invest.

(c) The American Society for Clinical Investigation, Inc. 0021-9738/89/09/0922/09 \$2.00

Volume 84, September 1989, 922-930 acute episodes or smouldering chronic activity of SLE perpetuate immune glomerular inflammation. It is also possible, however, that portions of the glomerular capillary bed might be permanently obliterated as a consequence of a single, acute episode when glomerulonephritis is severe. Notwithstanding suppression by effective therapy of SLE and immune glomerular inflammation, a diminished population of remnant glomeruli could then undergo destruction by nonimmunologic mechanisms that are independent of the initiating insult (6).

We have shown previously that total lymphoid irradiation (TLI) leads to protracted suppression of activity of SLE and sustained quiescence of lupus nephritis (7-9). The purpose of this study was to characterize the course and outcome of postnephritic glomerular injury under these circumstances. We combined physiologic with morphometric techniques to evaluate in longitudinal fashion for up to 36 mo the nature and extent of residual glomerular damage.

\section{Methods}

Patient population. Between 1979 and 1985, 10 patients with biopsy proven DPLN (World Health Organization, class IV) were consecutively subjected to TLI because of the development of a nephrotic syndrome that was refractory to corticosteroid therapy (9). All patients statisfied the criteria of the American Rheumatism Association for the diagnosis of SLE. The group consisted of seven females and three males, was aged between 17 and $44 \mathrm{yr}$ and had been known to have SLE for between 7 and 132 mo (median duration $72 \mathrm{mo}$ ). Each patient had experienced between 1 and 6 earlier episodes of active nephritis (median 3.5) before the current episode for which the TLI was administered.

Fractions of irradiation were delivered sequentially to supra- (200 rad each) and subdiaphragmatic lymphoid tissues (150 rad each) over a $32-\mathrm{d}$ period to a total dose of $2,000 \mathrm{rad}$, as described previously (7-9). The kidneys were shielded with lead so as to exclude them from the fields subjected to irradiation. Prednisone was administered in a daily dosage of $0.5 \mathrm{mg} / \mathrm{kg}$ throughout the period of irradiation, and tapered gradually thereafter. As described in detail elsewhere (7-9), TLI was followed uniformly within 3-6 mo by suppression of extrarenal manifestations and serologic activity of SLE. A prolonged state of immunosuppression (summarized in Table I) eventuated in the wake of TLI. Lymphocytopenia, most marked for $\mathrm{CD}^{+} \mathrm{T}$ cells, accompanied by diminished proliferation of lymphocytes in response to phytohemagglutin in vitro remained evident for $24 \mathrm{mo}$. Although $\mathrm{T}$ cell number and function tended to normalize in the third post-TLI year, the SLE remained quiescent. Beyond 12 mo post-TLI levels of antiDNA antibodies and of the third component of complement in serum were persistently in the normal range (Table I); clinical manifestations clearly attributable to active SLE included arthralgias, arthritis, fever, myalgias, serositis and alopecia. All of these became inconspicuous throughout the 36-mo posttreatment period of observation. The absence of serologic or clinical stigmata of active SLE permitted us to lower the maintenance dosage of prednisone to $<10 \mathrm{mg}$ per $24 \mathrm{~h}$ on average, for the last $\mathbf{2 4}$ mo of observation (Table I).

Physiologic determinations. Differential solute clearances were performed immediately before administration of TLI, and repeated 12 and 36 mo post-TLI. $7 \mathrm{~d}$ after antihypertensive and diuretic agents had been discontinued, all patients were admitted to a clinical research 


\begin{tabular}{|c|c|c|c|c|c|}
\hline & \multirow{2}{*}{$\begin{array}{l}\text { Healthy } \\
\text { controls }\end{array}$} & \multicolumn{4}{|c|}{ Lupus nephritis } \\
\hline & & Pre-TLI & 12 mo Post-TLI & 24 mo Post-TLI & 36 mo Post-TLI \\
\hline $\mathrm{CD}^{+} \mathrm{T}$ cells $/ \mathrm{mm}^{3}$ & $1,520 \pm 49$ & $624 \pm 135^{*}$ & $364 \pm 112^{*}$ & $667 \pm 141^{*}$ & $844 \pm 131^{*}$ \\
\hline $\mathrm{CD} 4^{+} \mathrm{T}$ cells $/ \mathrm{mm}^{3}$ & $870 \pm 69$ & $362 \pm 125^{*}$ & $166 \pm 57^{*}$ & $280 \pm 64^{*}$ & $463 \pm 81^{*}$ \\
\hline PBMC response to PHA $\left(\mathrm{cpm} \times 10^{3}\right)$ & $50.4 \pm 6.3$ & $65.9 \pm 20.0$ & $12.7 \pm 3.4^{* \pm}$ & $22.1 \pm 4.9^{* \pm}$ & $40.4 \pm 12.2$ \\
\hline Serum $C^{\prime} 3(m g / d l)$ & $90-125$ & $82 \pm 9$ & $128 \pm 11^{\ddagger}$ & $124 \pm 9^{\ddagger}$ & $124 \pm 9^{\ddagger}$ \\
\hline Anti-ds DNA $(U / m l)$ & $<25$ & $59 \pm 19$ & $21 \pm 5^{\ddagger}$ & $17 \pm 3^{\ddagger}$ & $20 \pm 5^{\ddagger}$ \\
\hline Prednisone dose $(m g / 24 h)$ & & $39 \pm 5$ & $18 \pm 2^{\ddagger}$ & $7 \pm 2^{\ddagger}$ & $9 \pm 3^{\ddagger}$ \\
\hline
\end{tabular}

${ }^{*} P<0.05$ vs. Control. ${ }^{\ddagger} P<0.05$ vs. Pre-TLI. $\mathrm{CD}^{+}$and $\mathrm{CD}^{+}$are total and helper $\mathrm{T}$ cells, respectively. $\mathrm{C}^{\prime} 3$, third component of complement. ds DNA, double-stranded desoxyribonucleic acid.

center. The clearance study was commenced at 0800 hours, after each patient had given informed consent to a protocol that had been approved previously by the Institutional Review Board at Stanford University. Urine was voided spontaneously after diuresis had been established with an oral water load $(15 \mathrm{ml} / \mathrm{kg})$. A priming dose of inulin (50 $\mathrm{mg} / \mathrm{kg}$ ) and para-aminohippuric acid (PAH, $12 \mathrm{mg} / \mathrm{kg}$ ) was then administered. Thereafter, inulin and PAH were given by continuous infusion to maintain plasma levels constant at 20 and $1.5 \mathrm{mg} / \mathrm{dl}$, respectively. With the exception of two patients with a past history of drug allergy, the inulin/PAH prime was followed by a 10-min intravenous infusion of dextran $40(130 \mathrm{mg} / \mathrm{kg})$.

$60 \mathrm{~min}$ after the priming infusion, arterial blood pressure was determined, and blood was sampled for examination of plasma oncotic pressure and plasma protein concentration. Four timed urine collections were then made, each of which was bracketed by a blood sample drawn from a peripheral vein. The glomerular filtration rate (GFR) was expressed as the average value for the four timed inulin clearances. The rate of renal plasma flow was estimated from the corresponding clearance of PAH. To correct for the depression of renal PAH extraction observed by ourselves and others in the presence of proteinuric glomerulopathy, renal plasma flow was calculated by dividing PAH clearance by an assumed extraction ratio of $0.7(10-15)$. Fractional macromolecule clearances $\left(\theta_{m}\right)$ were computed from the first timed collection using the equation: $\theta_{\mathrm{m}}=(U / P)_{\mathrm{m}} /(U / P)_{\mathrm{in}},(U / P)_{\mathrm{m}}$ and $(U / P)_{\text {in }}$ refer to the urine-to-midpoint plasma concentration ratio of the macromolecule (dextran, albumin, or IgG) and of inulin, respectively. The concentrations of inulin and PAH were determined with an automated assay $(8,10)$. Concentrations of dextran were assayed with anthrone after plasma and urine had been separated into $2-\AA$ fractions by gel permeation chromatography on precalibrated Ultragel AcA44 columns (LKB Instrument Co., Pleasant Hill, CA) $(10,11)$. Concentrations of albumin and IgG in serum were determined by radial immunodiffusion, while corresponding urinary concentrations were measured using a sensitive enzyme-linked immunosorbent assay that has been described elsewhere (16). Plasma oncotic pressure was measured directly using a membrane osmometer (Weil Oncometer; Instrumentation Laboratories, Inc., Lexington, MA).

Analysis of glomerular membrane-pore structure. To analyze the size-selective properties of the glomerular filtration barrier in terms of equivalent membrane-pore sizes, we applied the fractional clearances of dextrans in the 28-60 $\AA$ interval to a heteroporous model of the glomerular capillary wall that has been described in detail previously (17). In this model the major portion of the capillary wall is assumed to be perforated by restrictive, cylindrical pores of identical radius $\left(r_{0}\right)$. The model assumes that there exists in addition a parallel "shunt pathway" which does not discriminate on the basis of dextran size (up to $60 \AA \AA)$, and through which passes a small fraction of the filtrate volume. The shunt pathway is characterized by a parameter $\omega_{0}$, which governs the fraction of the filtrate volume passing through this nonrestrictive portion of the membrane. Specifically, $\omega_{0}$ is the fraction of the filtrate volume that would pass through the nonselective pores in the absence of a transmembrane oncotic pressure difference. As discussed in detail elsewhere, the actual fraction of the filtrate volume passing through these pores is calculated to slightly exceed $\omega_{0}$, because fluid movement through the small pores is retarded by the capillary oncotic pressure, whereas that through the large pores is not (17). This "isoporous with shunt" model has been shown to provide a more satisfactory representation of dextran fractional clearances in humans than an isoporous model or several other alternative heteroporous models. According to this model, the membrane barrier to filtration of water and uncharged macromolecules is characterized fully by the values of $r_{0}, \omega_{0}$, and $K_{f}$, where $K_{f}$ is the product of effective hydraulic permeability and total glomerular capillary surface area (for two kidneys). The approach used for calculating these intrinsic membrane parameters separates their effects on dextran fractional clearance from those of purely hemodynamic changes.

Morphometric evaluation. The diagnosis of active DPLN was made by light microscopic examination of renal biopsy material obtained within the 3 mo preceding TLI. Although hypercellularity of glomeruli was generalized in all cases, this finding along with an accumulation of mesangial matrix was confined in most glomeruli to discrete segments of the tuft. With the exception of one patient, who had a single kidney and underwent an open surgical biopsy pre-TLI, all patients were requested to undergo serial closed needle biopsies 12 and 36 mo postTLI. Three patients refused to undergo repeat biopsy, one at $12 \mathrm{mo}$ and the other two at 36 mo post-TLI. Thus, the total number of biopsies available for examination at each of these latter intervals was eight and seven, respectively. To permit a quantitative analysis of the morphological abnormalities associated with DPLN, six healthy kidney donors were biopsied at the time of transplantation. Their renal tissue provides control values for the morphometric quantities of interest.

Tissue was processed for light and fine ultrastructural study. For light microscopy, a single $1-\mu \mathrm{m}$ section stained with periodic-acid Schiff reagent was used, provided it contained $>15$ glomerular profiles. When fewer profiles were available a second $1-\mu \mathrm{m}$ section at a distance of 90-150 $\mu \mathrm{m}$ from the first was examined. In all, 460 glomerular sections in the 25 biopsies of DPLN patients were examined (range 12-43, mean 18). The corresponding number of glomerular profiles among the six control biopsies was 149 (range 15-65, mean 25 ). The respective numbers of open and closed glomerular tufts were recorded. Closed glomeruli were defined as those exhibiting global sclerosis. The remaining open glomeruli (remnants) included those in which inflammatory changes and/or sclerosis were segmental, leaving at least a portion of the capillary tuft patent.

The outline of each glomerular tuft in each biopsy core was traced onto a digitizing tablet at 900 magnification (16). The lumina of all patent glomerular capillary loops in each tuft were next traced in similar fashion at $\times 1,800$ (Fig. 1). Glomerular tuft cross-sectional area and the fractional tuft area occupied by patent capillary loops, were 

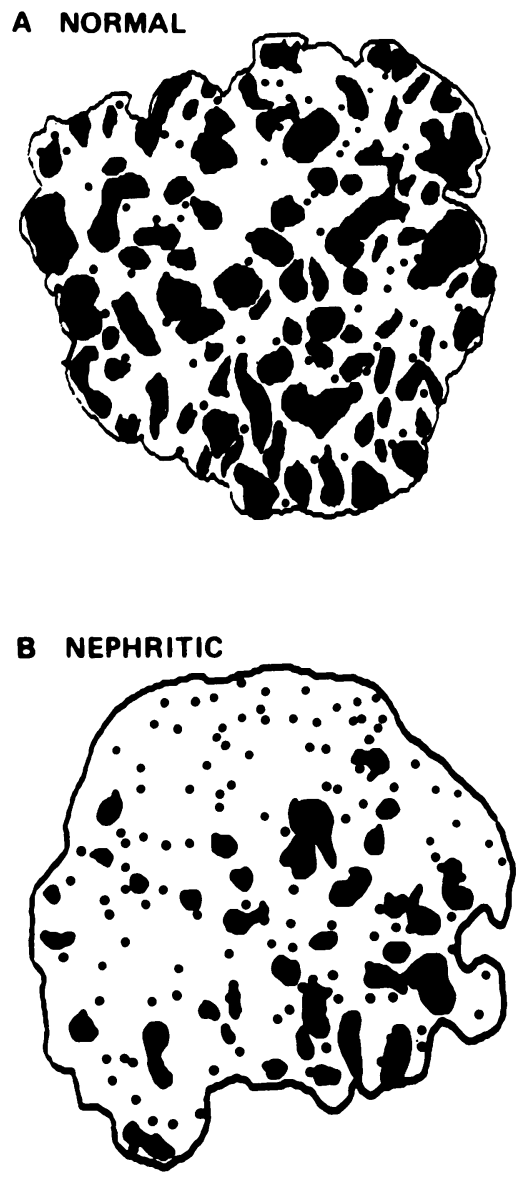

repeated measures that takes missing data into account was used to test the significance of differences in morphometric values post- vs. preTLI. Differences were regarded as significant when $P<0.05$. All results are expressed as the mean $\pm 1 \mathrm{SE}$.

\section{Results}

Dynamics of glomerular filtration. Individual values of GFR during the course of the study are illustrated in Fig. 2. The GFR at 12 mo increased markedly above the pre-TLI level in five subjects but remained relatively constant in the remainder. On average the GFR increased from $42 \pm 6$ to $54 \pm 7$ $\mathrm{ml} / \mathrm{min}$ per $1.73 \mathrm{~m}^{2}$ during the first 12 -mo interval (Table II). A different trend was observed between the 12- and 36-mo studies. Whereas GFR continued to rise modestly in two subjects, it declined in the remaining 8 . Because one patient was progressing rapidly to end-stage renal failure, the last set of measurements was advanced to 28 instead of $36 \mathrm{mo}$ in this instance. On average, GFR during the late 12-36-mo interval fell from $54 \pm 7$ to $45 \pm 9 \mathrm{ml} / \mathrm{min}$ per $1.73 \mathrm{~m}^{2}$.

The initial depression of GFR during active DPLN cannot be accounted for by alterations of either renal plasma flow or oncotic pressure. Whereas the pre-TLI GFR was depressed by $>50 \%$ below the control value in our laboratory for agematched controls $\left(108 \pm 3 \mathrm{ml} / \mathrm{min}\right.$ per $\left.1.73 \mathrm{~m}^{2}\right)$, renal plasma flow was not different from our control value $(571 \pm 54$ vs. $582 \pm 24 \mathrm{ml} / \mathrm{min}$ per $1.73 \mathrm{~m}^{2}$ ). Furthermore, reflecting the hypoproteinemia of these nephrotic subjects, plasma oncotic pressure was profoundly depressed to only $14.3 \pm 1.0 \mathrm{mmHg}$ (normal $23.5 \pm 1.0 \mathrm{mmHg}$ ). The latter phenomenon should enhance and not lower the GFR. The changes in renal plasma flow and oncotic pressure during the first 12 mo post-TLI were also discordant with the corresponding trend toward higher GFR. With only one exception renal plasma flow declined, on average, from $571 \pm 54$ to $424 \pm 50 \mathrm{ml} / \mathrm{min}$ per $1.73 \mathrm{~m}^{2}(P$ $<0.005$ ). Without exception plasma oncotic pressure became elevated, on average by $40 \%(P<0.001)$. Only in the late interval between 12 and 36 mo post-TLI did GFR and renal plasma flow fall in parallel (Table II).

In keeping with the observations of Kallenberg et al. in patients with resolving lupus nephritis (20), the most striking alteration of the glomerular filtration process in the wake of TLI was a marked elevation of the filtration fraction from 0.07 to 0.13 , on average (normal $=0.18 \pm 0.01$ ). On its own, the sustained elevation of oncotic pressure post-TLI should have lowered and not elevated the filtration fraction. By exclusion, TLI-induced inactivation of the underlying SLE must have enhanced the filtration fraction by increasing either the glomerular transcapillary hydraulic pressure difference $(\Delta \mathrm{P})$ or

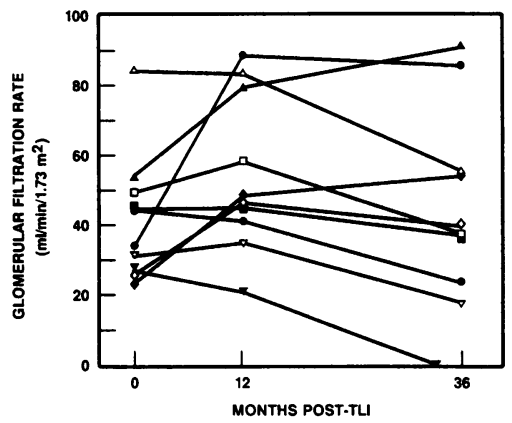

Figure 2. Serial GFR determinations in experimental population before TLI (time 0 ) and 12 and 36 mo post-TLI. 
Table II. Filtration Dynamics

\begin{tabular}{lccc}
\hline & Pre-TLI & 12 mo Post-TLI & 36 mo Post-TLI \\
\hline $\begin{array}{c}\text { Glomerular filtration rate } \\
\left(\mathrm{ml} / \text { min per } 1.73 \mathrm{~m}^{2}\right)\end{array}$ & $42 \pm 6$ & $54 \pm 7$ & $45 \pm 9$ \\
$\begin{array}{c}\text { Renal plasma flow } \\
\left(\mathrm{ml} / \text { min per } 1.73 \mathrm{~m}^{2}\right)\end{array}$ & $571 \pm 54$ & $424 \pm 50^{*}$ & $325 \pm 52^{* *}$ \\
$\begin{array}{l}\text { Filtration fraction } \\
\text { Plasma oncotic pressure } \\
(\mathrm{mmHg})\end{array}$ & $0.07 \pm 0.01$ & $0.13 \pm 0.01^{*}$ & $0.13 \pm 0.01^{*}$ \\
$\begin{array}{c}\text { Mean arterial pressure } \\
(\mathrm{mmHg})\end{array}$ & $14 \pm 1$ & $20 \pm 1^{*}$ & $21 \pm 1^{*}$ \\
\hline
\end{tabular}

Abbreviations: GFR, glomerular filtration rate; RPF, renal plasma

flow.

* $P<0.01$ vs. Pre-TLI

${ }^{\ddagger} P<0.05$ vs. 12 mo post-TLI.

the glomerular ultrafiltration coefficient $\left(K_{\mathrm{f}}\right)$, or by some combination of these two possibilities (21). It should be noted that arterial pressure, an important determinant of $\Delta \mathrm{P}$, was elevated pre-TLI and did not change significantly post-TLI (Table II).

Glomerular barrier function. In contrast to its variable effect on GFR, TLI was followed by a marked and sustained improvement in glomerular barrier function (Table III). Urinary losses of both albumin and IgG diminished uniformly from nephrotic to subnephrotic levels with an attendant increase in the serum concentration of each protein $(P<0.01$, Table III). The fractional clearance of each protein at 12 mo was 5 to 10 times lower than the pretreatment value, and the improvement was maintained at 36 mo post-TLI.

There was also a marked alteration in the sieving behavior of glomeruli towards polydisperse, uncharged dextrans following TLI. Whereas fractional clearances of relatively permeant dextrans of radius $<50 \AA$ were unaltered, there was a significant reduction in fractional clearances of nearly impermeant dextrans of radius $>50 \AA$. The selective depression of the large radius end of the dextran sieving profile was more marked at 36 than at 12 mo (Fig. 3). Thus, diminishing urinary protein

Table III. Protein Excretion and Clearance

\begin{tabular}{lrcc}
\hline & Pre-TLI & $\begin{array}{c}12 \text { mo } \\
\text { Post-TLI }\end{array}$ & $\begin{array}{c}36 \text { mo } \\
\text { Post-TLI }\end{array}$ \\
\hline $\begin{array}{l}\text { Urinary albumin } \\
\text { excretion }(\mu g / m l)\end{array}$ & $5,832 \pm 1,378$ & $1,898 \pm 425^{*}$ & $1,331 \pm 384^{* \neq}$ \\
$\begin{array}{l}\text { Urinary IgG excretion } \\
\quad(\mu g / m i n)\end{array}$ & $345 \pm 104$ & $69 \pm 29^{*}$ & $113 \pm 45^{*}$ \\
$\begin{array}{l}\text { Serum albumin }(m g / d l) \\
\text { Serum IgG }(m g / d l)\end{array}$ & $2,333 \pm 261$ & $3,160 \pm 258^{*}$ & $3,441 \pm 205^{*}$ \\
$\begin{array}{l}\text { Fractional albumin } \\
\text { clearance }\left(\times 10^{-5}\right)\end{array}$ & $541 \pm 133$ & $687 \pm 112$ & $946 \pm 169^{* \neq}$ \\
$\begin{array}{l}\text { Fractional IgG clearance } \\
\left(\times 10^{-5}\right)\end{array}$ & $750 \pm 180$ & $180 \pm 10^{*}$ & $140 \pm 10^{*}$ \\
\hline
\end{tabular}

$* P<0.05$ vs. pre-TLI.

${ }^{\ddagger} P<0.05$ vs. 12 mo post-TLI.

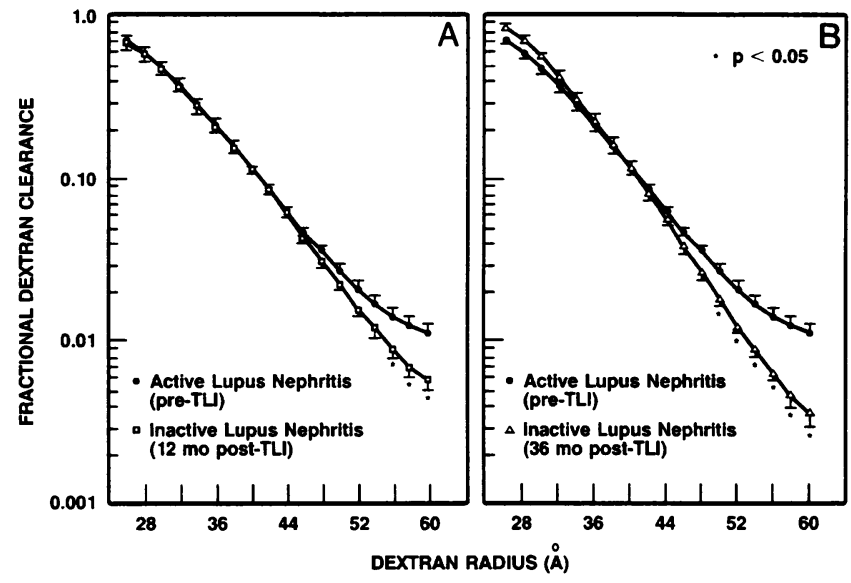

Figure 3. Dextran sieving profiles $12 \mathrm{mo}(A)$ and 36 mo post-TLI $(B)$ are depicted by open symbols. Each is compared to the corresponding profile before TLI (closed symbols).

losses in the wake of TLI were associated with improvement in the size-selective properties of the glomerular barrier.

Analysis of glomerular membrane parameters. The dextran sieving profiles were used to compute values of membrane parameters for the glomerular capillary wall at each study interval. To allow for the influence of hemodynamic factors on convective and diffusive transmembrane dextran transport (22), we estimated the approximate value of $\Delta \mathrm{P}$ by using a curve fitting technique that has been described in detail previously $(23,24)$. In brief, possible values for $\Delta \mathrm{P}$ over a $25-45$ $\mathrm{mmHg}$ range were examined at $1-\mathrm{mmHg}$ intervals. Each $\Delta \mathrm{P}$ value was applied to the "isoporous with shunt" membrane model along with the measured mean dextran sieving profiles illustrated in Fig. 3, and the group values estimated for renal plasma flow and plasma (afferent) oncotic pressure in Table II. The sum of chi-squares between the fractional dextran clearance profiles predicted by the model and those actually observed was minimized at all three study times in the $\Delta \mathrm{P}$ interval $30-35 \mathrm{mmHg}$. Accordingly, these likely upper and lower bounds of $\Delta \mathbf{P}$ were used to compute membrane parameters from the dextran sieving profile at each study time.

The results of this analysis are summarized in Table IV. It reveals the major restrictive component of the glomerular capillary wall to have been perforated by pores of unchanging radius $\left(r_{0} \sim 56 \AA\right)$ at all three study times. By contrast, the nonrestrictive shunt pathway is computed to have become

Table IV. Membrane Parameters

\begin{tabular}{lcccc}
\hline & $\Delta \mathrm{P}$ & Pre-TLI & $\begin{array}{c}12 \mathrm{mo} \\
\text { Post-TLI }\end{array}$ & $\begin{array}{c}36 \mathrm{mo} \\
\text { Post-TLI }\end{array}$ \\
\hline & $m m H g$ & & & \\
$K_{\mathrm{f}}(\mathrm{ml} / \mathrm{min} \cdot \mathrm{mmHg})$ & 30 & 2.8 & 7.2 & 6.5 \\
& 35 & 2.1 & 4.3 & 3.7 \\
Restrictive pore radius $\left(r_{0}, \AA\right)$ & 30 & 56.0 & 55.7 & 55.7 \\
& 35 & 56.1 & 56.1 & 56.0 \\
Fraction filtrate shunted $\left(\omega_{0}\right)$ & 30 & 0.010 & 0.003 & 0.002 \\
& 35 & 0.011 & 0.004 & 0.002
\end{tabular}




\begin{tabular}{|c|c|c|c|c|}
\hline & \multirow[b]{2}{*}{ Healthy controls } & \multirow[b]{2}{*}{ Pre-TLI } & \multicolumn{2}{|c|}{ Post-TLI } \\
\hline & & & $12 \mathrm{mo}$ & $36 \mathrm{mo}$ \\
\hline & $n=6$ & $n=10$ & $n=8$ & $n=7$ \\
\hline Cell density (per 1,000 $\mu^{2}{ }^{2}$ tuft area) & $3.08 \pm 0.17^{*}$ & $5.05 \pm 0.43$ & $4.12 \pm 0.33$ & $3.14 \pm 0.39^{*}$ \\
\hline$\%$ of basement membrane occupied by deposits & $0^{*}$ & $10.3 \pm 1.6$ & $6.2 \pm 2.0^{*}$ & $4.0 \pm 1.2^{*}$ \\
\hline Fractional patent loop area & $0.30 \pm 0.01^{*}$ & $0.11 \pm 0.01$ & $0.20 \pm 0.01^{*}$ & $0.19 \pm 0.02 *$ \\
\hline Filtration slit frequency (per $\mu m$ loop length) & $1.16 \pm 0.08^{*}$ & $0.81 \pm 0.07$ & $0.98 \pm 0.06^{*}$ & $0.80 \pm 0.08^{\ddagger}$ \\
\hline Ratio area to length of peripheral basement membrane $(\mu \mathrm{m})$ & $0.50 \pm 0.02^{*}$ & $1.09 \pm 0.16$ & $1.00 \pm 0.15$ & $0.98 \pm 0.09$ \\
\hline
\end{tabular}

${ }^{*} P<0.05$ vs. pre-TLI. ${ }^{\ddagger} P<0.05$ vs. 12 mo post-TLI.

much less prominent in the wake of TLI. Whereas the fraction of filtrate volume permeating the shunt $\left(\omega_{0}\right)$ approximated $0.010-0.011$ before TLI, the corresponding values at 12 and 36 mo post-TLI averaged only $0.003-0.004$, and 0.002 , respectively. Transmembrane shunting of a smaller fraction of fluid that is macromolecule rich could provide a basis for the observed diminution in the magnitude of urinary protein losses following TLI. Because our computations of $\Delta \mathrm{P}$ may not be accurate to within several millimeters of mercury, the absolute values of $K_{\mathrm{f}}$ provided in Table IV are likely to be imprecise (23, 24). However, the model is useful in identifying relative changes in the direction of $K_{\mathrm{f}}(22)$. It seems likely therefore, that $K_{\mathrm{f}}$ was depressed profoundly during the active episode of DPLN, as has been found to be the case in experimental animals with glomerulonephritis (25-27). Previous estimates of this quantity in subjects with healthy kidneys in our laboratory have varied between 12 and $16 \mathrm{ml} /(\mathrm{min} \cdot \mathrm{mmHg}$ ) compared to the mean pre-TLI estimate of only $2.1-2.8 \mathrm{ml} /(\mathrm{min} \cdot \mathrm{mmHg})$ in the actively nephritic patients of the present study $(10,17$, 23). The computed two- to threefold increase of $K_{\mathrm{f}}$ at both study times post-TLI (Table IV) suggests that maintenance of GFR at the observed postnephritic levels was achieved despite a profound reduction of ultrafiltration pressure. From the quotient $G F R / K_{f}$, we estimate that glomerular ultrafiltration pressure fell from an initial value of $15-20 \mathrm{mmHg}$ during active DPLN to only 8-13 and 7-12 $\mathrm{mmHg}$, respectively, 12 and $36 \mathrm{mo}$ after inactivation of the SLE by TLI therapy.

Glomerular morphometry. An increase above control values of both glomerular cell density $(5.1 \pm 0.4$ vs. $3.1 \pm 0.2$ cells per $1,000 \mu \mathrm{m}^{2}$ of glomerular tuft area, $P<0.001$ ) and the percentage of GBM area occupied by electron dense deposits $(10.3 \pm 1.6$ vs. $0.0 \%)$ attest to the activity of DPLN before treatment (Table V). Cell density decreased progressively at the 12- and 36-mo examinations, returning to the control level at the latter examination. The percent of GBM area occupied by electron-dense immune deposits fell in parallel, to $6.2 \pm 2.0$ at $12 \mathrm{mo}$ and to only $4.0 \pm 1.2 \%$ by $36 \mathrm{mo}$ (Table V). In addition to becoming sparse the deposits no longer appeared fresh in the 36-mo biopsy. Whereas immune deposits occupied the inner or outer rare layers of the GBM during active DPLN, almost all immune deposits observed in 36-mo biopsies were intramembranous, and appeared to have become enveloped by newly laid down basement membrane.

Despite the foregoing evidence of receding glomerular inflammation post-TLI, the morphometric examination of glomerular tuft area revealed an increasing trend toward bimodal- ity of glomerular size distribution with the passage of time (Fig. 4). The cross-sectional area of glomerular tufts in the healthy kidney donors was rather narrowly distributed around a mode of between 6 and 12,000 $\mu \mathrm{m}^{2}$ (upper histogram, Fig. 4). This narrow distribution was lost with the development of active lupus nephritis, however. Glomerular tuft area was shifted to both smaller and larger size (middle histogram, Fig. 4). The trend toward smaller and larger glomerular area became progressively more pronounced at $12 \mathrm{mo}$ (not shown) and $36 \mathrm{mo}$ post-TLI (bottom histogram, Fig. 4). Whereas glomerular tuft area was below $6,000 \mu \mathrm{m}^{2}$ in only $17 \%$ of glomeruli in control tissue from healthy kidney donors, the corresponding percentage was $23 \%$ during active DPLN, $28 \%$ at 12 mo post-TLI, and $44 \%$ at 36 mo TLI.

The increment in glomerular tufts of small area could be accounted for by the development of progressive global glomerulosclerosis (Fig. 4). Whereas globally sclerotic glomeruli were not encountered in control biopsies, the percentage of glomeruli exhibiting global sclerosis in the serial biopsies of patients with DPLN increased slightly from $22 \pm 7$ (pre-TLI) to $25 \pm 8 \%$ at $12 \mathrm{mo}$, and then substantially to $57 \pm 7 \%$ at $36 \mathrm{mo}$ post-TLI, respectively $(P<0.05$ vs. pre-TLI, Fig. 5). Also

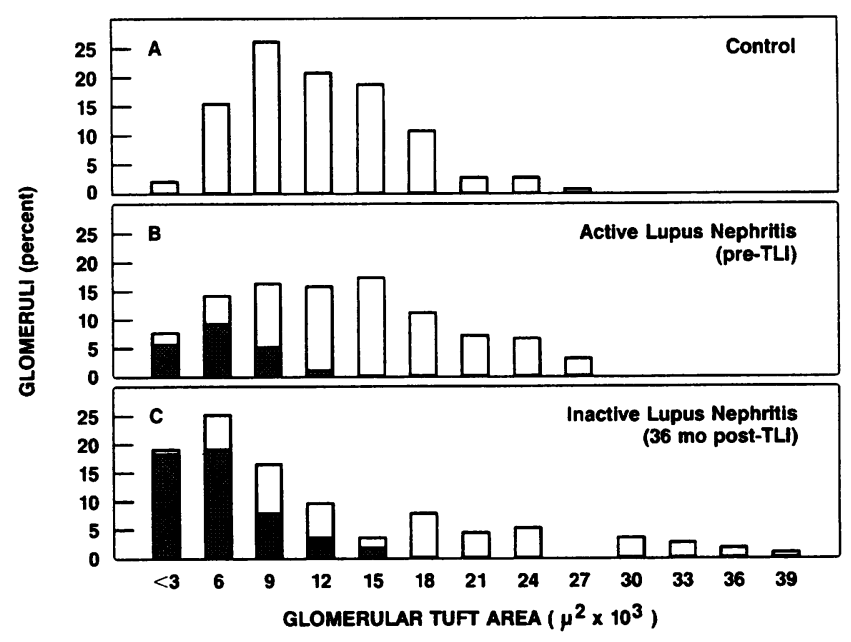

Figure 4. Distribution of glomerular cross-sectional area. Upper histogram depicts healthy control glomeruli; middle and lower histograms depict glomeruli from patients with DPLN before and 36 mo post-TLI, respectively. The shaded portions of the bars represent the percentage of globally sclerosed glomeruli at each interval. 

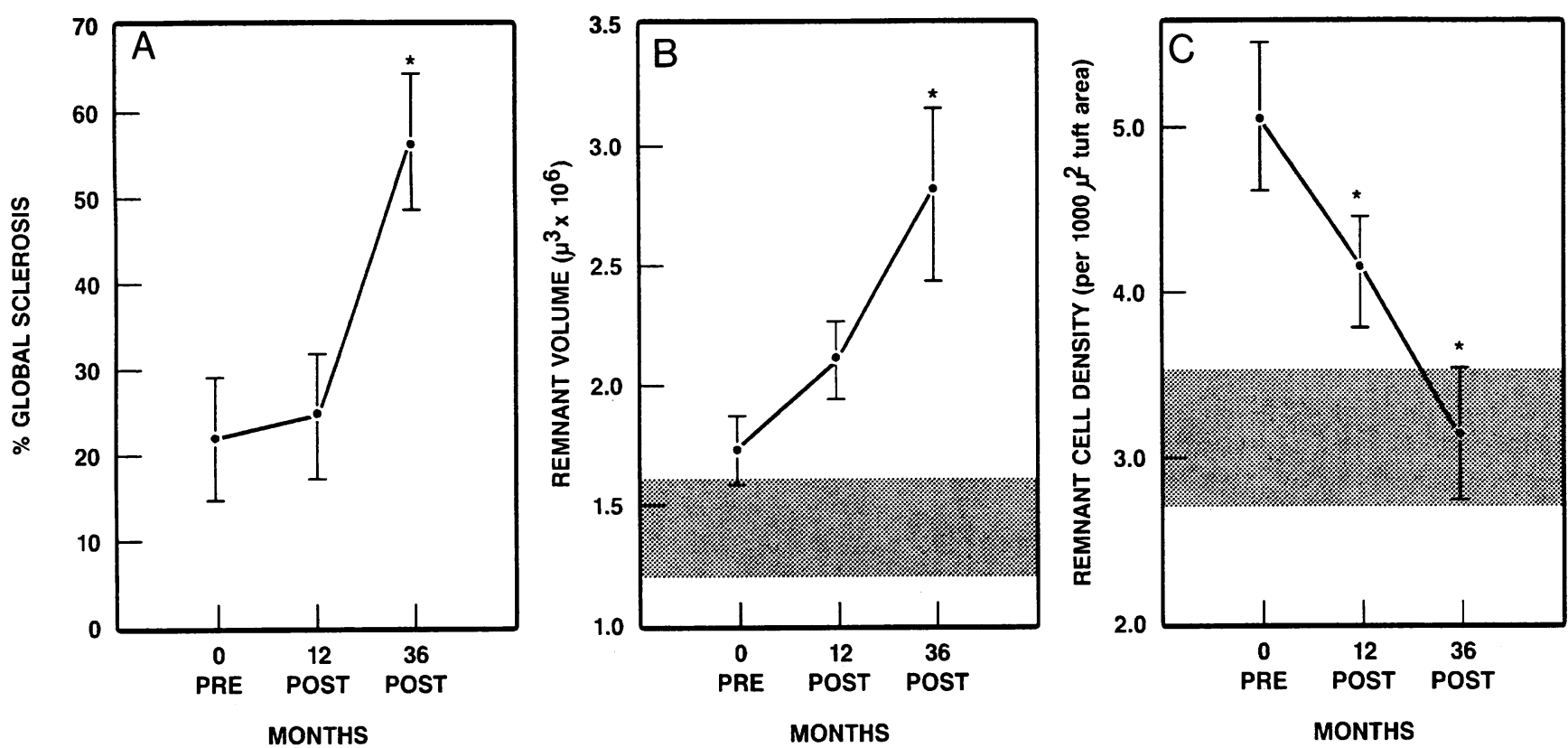

Figure 5. Serial changes in the percent of globally sclerotic glomeruli $(A)$, and the volume $(B)$, and cell density $(C)$ of remnant open glomeruli. Shaded zones represent normal range (mean $\pm 1 \mathrm{SD}$ ).

shown in Fig. 4 is that glomerular sclerosis and shrinkage in DPLN was accompanied by the appearance of a subpopulation of enlarged glomeruli of tuft area $>27,000 \mu \mathrm{m}^{2}$. Whereas this phenomenon was not observed in control kidneys or in pre-TLI DPLN, glomeruli of tuft area $>27,000 \mu \mathrm{m}^{2}$ comprised, respectively, 1.7 and $8.7 \%$ of the total glomerular population 12 and 36 mo post-TLI.

The mean volume of globally sclerotic glomeruli was significantly below the control value of $1.47 \pm 0.18$, averaging $0.35 \pm 0.06,0.37 \pm 0.11$, and $0.44 \pm 0.07 \mu \mathrm{m}^{3} \times 10^{6}$ during active DPLN and 12 and 36 mo post-TLI, respectively $(P<0.01)$. In contrast, a progressive increase in glomerular volume suggests that open, remnant glomeruli underwent generalized hypertrophy with the passage of time; $2.03 \pm 0.15$ and $2.69 \pm 0.34$ at 12 and $36 \mathrm{mo}$ post-TLI vs. $1.69 \pm 0.13, \mu \mathrm{m}^{3} \times 10^{6}$ before TLI $(P<0.05$ at $36 \mathrm{mo}$, Fig. 5).

That the initial reduction of GFR during active DPLN is caused by a diminution of surface area available for filtration is suggested by the fraction of glomerular area occupied by patent loops (Table V). Whereas fractional patent loop area averaged $0.30 \pm 0.01$ in control kidneys, the corresponding fraction was only $0.11 \pm 0.01$ during active DPLN $(P<0.001)$. Fractional patent loop area was greater by almost twofold at both 12 and 36 mo post-TLI examinations. This quantity was not restored to the control value however, reflecting a subpopulation of segmentally sclerosed glomeruli which represented $26 \pm 5,27 \pm 4$, and $23 \pm 8 \%$ of total at 0,12 , and $36 \mathrm{mo}$, respectively. Of importance, it should be emphasized that only open glomeruli were subjected to this determination. Thus, the prevailing GFR post-TLI appears to depend, at least in part, on the offsetting effects of increasing glomerular obliteration due to global sclerosis on the one hand, and the greater patency of capillary loops in open glomeruli on the other.

Of the two remaining morphometric quantities of interest (Table V) only filtration slit frequency tended to improve transiently after TLI. Judged by the ratio of GBM area to glomerular capillary loop length, the GBM was widened by twofold during active DPLN and remained similarly widened post-TLI, despite the gradual disappearance of electron dense deposits. Either the chronic reduction in filtration slit frequency or the persistent widening of the GBM may have contributed to sustained glomerular hypofiltration by lowering the hydraulic permeability of the walls of those glomerular capillaries that remained patent.

Late outcome of glomerular injury. As stated previously, end-stage renal failure developed in one of our patients $32 \mathrm{mo}$ after therapy with TLI. At the time of writing seven other members of the group have been followed beyond $3 \mathrm{yr}$ for periods of up to $7 \mathrm{yr}$ since the initiation of radiation therapy, and two of these have gone on to develop end-stage renal failure after 42 and $61 \mathrm{mo}$, respectively. Thus, despite effective therapy of the underlying SLE, there has been significant attrition in the number of patients with functioning kidneys among our patient population. This bleak outcome is consistent with the observations of Appel et al., who reported a 50\% incidence of end-stage renal failure within a decade among immunosuppressed patients with DPLN who presented with a nephrotic syndrome, as was the case in the subjects of the present study (5). ${ }^{2}$

\section{Discussion}

Our morphometric analysis of serial renal biopsies suggests strongly that immune glomerular inflammation subsides when activity of SLE is chronically suppressed by TLI and maintenance corticosteroid therapy in patients with DPLN. Both the

2. Ten tables containing individual findings at each study time for filtration dynamics, glomerular barrier function, and glomerular morphometry have been deposited with the Library of Congress. Copies can be obtained by contacting the Interlibrary Photocopy Service from the Library of Congress. 
density of glomerular cells and of immune deposits along the glomerular capillary walls declined markedly during the 36-mo period of observation. Among the physiologic variables studied, glomerular barrier function appears to correlate best with subsiding glomerular inflammation. A selective lowering of transglomerular passage of nearly impermeant dextrans of radius above $50 \AA$ points to an improvement in barrier size-selectivity. According to our theoretical model the alteration in the size-selective barrier was confined to a subpopulation of enlarged pores that are few in number but nondiscriminating towards dextrans of up to $60 \AA$ radius (17). A four- to fivefold decrease in the volume of macromolecule-rich fluid being shunted through these enlarged pores could have contributed substantially to the observed, posttreatment reduction in the magnitude of proteinuria.

Despite subsiding glomerular inflammation and diminished transcapillary sieving of large plasma proteins, only 5 of 10 patients exhibited a substantial increase in GFR (Fig. 1). In three of the five the increment in GFR was transient, moreover. On average, the response of GFR to inactivation of DPLN was rather modest and followed a biphasic course. In evaluating this response, it is useful to consider the individual determinants of the rate at which glomerular ultrafiltrate is formed.

The GFR can be equated with the product of net ultrafiltration pressure and an ultrafiltration coefficient, $K_{\mathrm{f}}(21)$. Our analysis of transglomerular dextran flux suggests that $\Delta \mathrm{P}$, the positive driving force for filtration, remained relatively constant over the 36-mo period of observation. However, a lower flow rate and elevated oncotic pressure of plasma entering the glomerular tufts after TLI therapy is predicted to have elevated the intraluminal oncotic pressure along the entire length of the glomerular capillary networks (21). Elevation of this opposing force would serve to lower the net pressure for glomerular ultrafiltration. By exclusion, the trend towards higher GFR 12 mo post-TLI is likely attributable to an increase in $K_{\mathrm{f}}$. It is worthy of emphasis that the reduced intensity of immune inflammation and lower load of filtered protein observed $12 \mathrm{mo}$ post-TLI may have been associated with improved PAH extraction. In this circumstance, the reduction in RPF and corresponding increment in $K_{\mathrm{f}}$ would be even greater than suggested by the calculated values in Tables II and IV, respectively. From the constancy of the filtration fraction and the oncotic pressure of plasma between 12 and 36 mo post-TLI, we infer that a further elevation of glomerular intracapillary oncotic pressure did not eventuate in this latter interval. It follows that a secondary decline in $K_{\mathrm{f}}$ most likely underlies the late fall in GFR observed in 8 of our 10 subjects (Fig. 1).

As stated previously, $K_{\mathrm{f}}$ is here defined as the product of effective hydraulic permeability and the total glomerular capillary surface area available for filtration in the two kidneys. Either a twofold widening of the GBM or a reduction in the frequency of filtration slits could have lowered hydraulic permeability by respectively lengthening or compromising the transcapillary pathway for water flux. Of these two ultrastructural alterations, the filtration slit frequency seems the more likely to have influenced the GFR for two reasons. The first is that the broadening of epithelial foot processes that underlies the observed lowering of filtration slit frequency has been strongly related to the prevailing GFR in a variety of other human glomerulopathies $(10,28,29)$. The second is that postTLI filtration slit frequency varied in parallel with the trend toward an early rise in GFR at $12 \mathrm{mo}$, followed by a late fall in this quantity after 36 mo (Table V). While an effect of foot process broadening to lower hydraulic permeability may have contributed to the prevailing GFR however, our findings suggest that changes in filtration surface area are more likely to have had a predominant role during the post-TLI followup period in the present study.

During the 12-mo interval after TLI, the fraction of glomerular tuft area that was occupied by patent capillary loops almost doubled (Table V). Although indirect, the restoration of previously occluded capillary loops to patency is strongly suggestive of an increase in filtration surface area, and could account for the initial trend towards higher GFR at $12 \mathrm{mo}$. The fractional patent loop area of open glomeruli remained constant between 12 and 36 mo. However, there was a considerable increase in the percentage of glomeruli that had undergone global sclerosis by this time (Figs. 4 and 5). Because large glomeruli are more likely to appear in a given cross-section than small glomeruli, our estimate of an increasing fraction of shrunken, sclerosed glomeruli with the passage of time is likely to be, if anything, an underestimate $(18,19)$. An increasing prevalence of sclerotic glomeruli could have served to offset the earlier gain in filtration surface area as loop patency increased in remnant, open glomeruli. Progressive glomerulosclerosis in turn, could then explain the late trend toward declining GFR beyond 12 mo post-TLI.

Our finding that progressive glomerulosclerosis only becomes manifest more than 12 mo after active DPLN has been suppressed is especially noteworthy. We can only speculate as to the sequence of events that underlies the apparent delay between the phenomenon of intense glomerular inflammation and the development of progressive glomerulosclerosis. A possible course of injury that could account for our serial observations is outlined schematically in Fig. 6.

According to this scheme, the fate of individual glomeruli in DPLN depends on the extent of the initial immune injury.

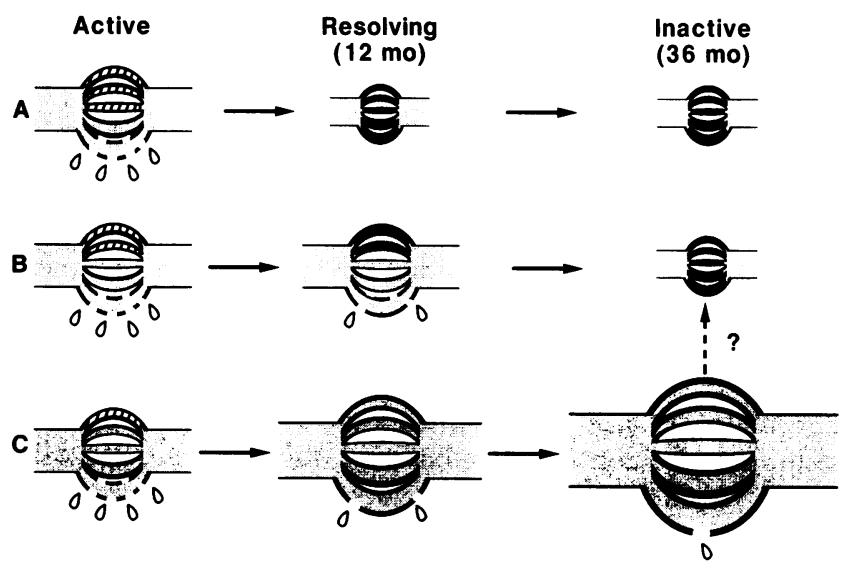

Figure 6. Hypothetical course of glomerular injury in DPLN: three categories of injury are postulated according to whether the extent of tuft obliteration by active nephritis (hatched loops) is severe $(A)$, intermediate $(B)$, or mild $(C)$. The adjacent spheres reflect the magnitude of protein leakage. Category $A$ is proposed to lead rapidly and category B slowly to global sclerosis (solid loops). Only category C injury is inferred to resolve completely. Factors associated with subsequent hypertrophy of category $\mathrm{C}$ glomeruli (middle and right) may contribute to progressive glomerulosclerosis. 
Active nephritic changes extensive enough to obliterate most loops (category A) are inferred to lead rapidly to global sclerosis, while intermediate loop obliteration (category B) is envisaged to heal with collagenization of the tuft that is at first segmental, but later becomes global. We postulate that only the capillary networks of the least extensively injured tufts (category C) are restored to patency when lupus nephritis is effectively suppressed, and that it is this category of relatively spared glomeruli that undergoes hypertrophy, presumably as part of an adaptive response to augment filtration surface area.

The hypothetical course of injury outlined above offers three possible explanations for the striking increment in the fraction of glomeruli exhibiting global sclerosis between 12 and 36 mo post-TLI. As suggested for category B glomeruli in Fig. 6, fully 36 mo may be required for glomeruli to become globally sclerosed when the initial extent of nephritic injury is intermediate. An alternative explanation is that relatively slow progression to global sclerosis in a subpopulation of glomeruli was promoted by persistent immune inflammation of a low grade that was not detectable by routine clinical examination or the conventional serological measures of lupus activity listed in Table I. A remaining possibility is that a mechanism unrelated to immune inflammation may promote progressive glomerulosclerosis following effective suppression of DPLN.

An example of nonimmunologically mediated glomerulosclerosis is that observed after extensive ablation of renal mass in the rat $(30,31)$. Remnant glomeruli in this circumstance are characterized by progressive hypertrophy, an adaptive increase in single nephron GFR and a propensity to undergo glomerulosclerosis. Analogous changes can be inferred between 12 and $36 \mathrm{mo}$ in the present study. The volume of open glomeruli between the two examinations increased by $33 \%$ (Fig. 5). Whereas the corresponding 2-kidney GFR declined by only $17 \%$ on average (Table II), there was a $42 \%$ reduction in the percentage of glomeruli in biopsy cross-sections that remained open; from $75 \%$ at 12 mo to only $43 \%$ at 36 mo (Fig. 5). The disparity between these latter findings suggests that remnant single nephron GFR had increased in the interim. As in remnant glomeruli in the postablation rat model, it is conceivable that adaptive hypertrophy of and hyperfiltration by relatively uninflamed glomeruli may have served as precursors to progressive glomerulosclerosis.

We wish to emphasize that the present findings do not permit us to distinguish between the aforementioned, possible mediators of postnephritic glomerulosclerosis. However, we note with interest that by 36 mo posttreatment immune inflammation was no longer discernable in our patients by either clinical, serological or morphological criteria. Serial study of such patients more than 36 mo after DPLN has become quiescent might provide an opportunity to better isolate a possible role for nonimmunological factors in promoting progressive glomerulosclerosis. Such factors, associated perhaps with adaptive hypertrophy of remnant glomeruli, could help explain the progression to end-stage renal failure that is often observed long after DPLN and other glomerulonephritides appear to have become inactive.

\section{Acknowledgments}

This study was supported by grants AM-29985 and DK-33340 from the National Institutes of Health, and General Clinical Research
Center grant M01-RR00070. Drs. Chagnac and Kiberd were Fellows of the National Kidney Foundation.

\section{References}

1. Felson, D. T., and J. Anderson. 1984. Evidence for the superiority of immunosuppressive drugs and prednisone over prednisone alone in lupus nephritis. N. Engl. J. Med. 311:1528-1533.

2. Balow, J. E., H. A. Austin, L. R. Muenz, K. M. Joyce, T. T. Antonovych, J. H. Klippel, A. D. Steinberg, P. H. Plotz, and J. L. Decker. 1984. Effect of treatment on the evolution of renal abnormalities in lupus nephritis. N. Engl. J. Med. 311:491-495.

3. Austin, H. A., J. H. Klippel, J. E. Balow, N. G. Le Riche, and A. D. Steinberg. 1986. Therapy of lupus nephritis. N. Engl. J. Med. 314:614-619.

4. Lewis, E. J., K. Kawala, and M. M. Schwartz. 1987. Histologic features that correlate with the prognosis of patients with lupus nephritis. Am. J. Kidney Dis. 10:192-197.

5. Appel, G. B., D. J. Cohen, C. L. Pirani, J. I. Meltzer, and D. Estes. 1987. Long-term follow-up of patients with lupus nephritis. A study based on the classification of the World Health Organization. Am. J. Med. 83:877-885.

6. Hostetter, T. H., H. G. Rennke, and B. M. Brenner. 1982. The case for intrarenal hypertension in the initiation and progression of diabetic and other glomerulopathies. Am. J. Med. 72:375-380.

7. Strober S., E. Field, R. T. Hoppe, B. Kotzin, O. Shemesh, E. Engleman, J. Ross, and B. D. Myers. 1985. Treatment of intractable lupus nephritis with total lymphoid irradiation. Ann. Intern. Med. 102:450-458.

8. Friedman, S., S. Strober, E. H. Field, E. Silverman, and B. D. Myers. 1984. Glomerular capillary wall function in human lupus nephritis. Am. J. Physiol. 246:F580-F591.

9. Strober, S., M. C. Fariñas, E. H. Field, J. J. Solovera, B. A. Kiberd, B. D. Myers, and R. T. Hoppe. 1988. Treatment of lupus nephritis with total lymphoid irradiation: observations during a 12 to 79 month follow up. Arthritis Rheum. 31:850-858.

10. Shemesh, O., J. C. Ross, W. M. Deen, G. W. Grant, and B. D. Myers. 1986. Nature of the glomerular capillary injury in human membranous glomerlopathy. J. Clin. Invest. 77:868-877.

11. Shemesh, O., W. M. Deen, B. M. Brenner, E. McNeely, and B. D. Myers. 1986. Effect of colloid volume expansion on glomerular barrier size-selectivity in humans. Kidney Int. 29:916-923.

12. Bradley, S. E., G. P. Bradley, C. J. Tyson, J. J. Curry, and W. D. Blake. 1950. Renal function in renal disease. Am. J. Med. 9:766-798.

13. Brodwall, E. K. 1960. Renal extraction of PAH in renal disease. Scand. J. Clin. Lab. Invest. 16:12-20.

14. Bergstrom, J., H. Bucht, B. Josephson, H. Sundell, and L. Werko. 1960. The renal extraction of para-aminohippurate in normal persons and in patients with diseased kidneys. Scand. J. Clin. Lab. Invest. 11:361-375.

15. Carghill, W. H. 1948. The measurement of glomerular and tubular plasma flow in the normal and diseased human kidney. J. Clin. Invest. 28:189-192.

16. Myers, B. D., R. Sibley, L. Newton, S. J. Tomlanovich, C. Boshkos, E. Stinson, J. A. Luetscher, D. J. Whitney, D. Krasny, N. S. Coplon, and M. G. Perlroth. 1988. The long-term course of cyclosporine-associated chronic nephropathy. Kidney Int. 33:590-600.

17. Deen, W. M., C. R. Bridges, B. M. Brenner, and B. D. Myers. 1985. A heteroporous model of size-selectivity: application to normal and nephrotic humans. Am. J. Physiol. 249:F347-F389.

18. Weibel, E. R. 1979. Stereological Methods. Academic Press, London. 1:40-57.

19. Hirose, K., R. Osterby, M. Nozawa, and H. J. G. Gundersen. 1982. Development of glomerular lesions in experimental long-term diabetes in the rat. Kidney Int. 21:688-695.

20. Kallenberg, C. G. M., C. Schweitzer, P. E. De Jong, A. J. 
Donker, and G. K. Van Der Hem. 1984. Decreased filtration fraction during active proliferative lupus nephritis: relation to disease activity and reversibility of renal function. Clin. Nephrol. 22:223-229.

21. Deen, W. M., C. R. Robertson, and B. M. Brenner. 1972. A model of glomerular ultrafiltration in the rat. Am. J. Physiol. 223:1178-1183.

22. Chang, R. L. S., I. F. Ueki, J. L. Troy, W. M. Deen, C. R. Robertson, and B. M. Brenner. 1975. Permselectivity of the glomerular capillary wall to macromolecules. I. Theoretical considerations. Biophys. J. 15:887-895.

23. Chan, A. Y. M., M. L. Cheng, L. C. Keil, and B. D. Myers. 1988. Functional response of healthy and diseased glomeruli to a large, protein-rich meal. J. Clin. Invest. 81:245-254.

24. Myers, B. D., C. Peterson, C. R. Molina, S. J. Tomlanovich, L. D. Newton, R. Nitkin, H. Sandler, and F. Murad. 1988. Role of cardiac atria in the human renal response to changing plasma volume. Am. J. Physiol. 23:F562-573.

25. Allison, M. E. M., C. B. Wilson, and C. W. Gotschalk. 1974. Pathophysiology of experimental glomerulonephritis in rats. J. Clin. Invest. 53:1402-1423.
26. Ichikawa, I., J. R. Hoyer, W. M. Seiler, and B. M. Brenner. 1982. Mechanisms of glomerulotubular balance in the setting of heterogeneous glomerular injury. J. Clin. Invest. 69:185-198.

27. Maddox, D. E., C. M. Bennett, W. M. Deen, R. J. Glassock, D. Knutson, T. M. Daugharty, and B. M. Brenner. 1975. Determinants of glomerular filtration in experimental glomerulonephritis in the rat. $J$. Clin. Invest. 55:305-318.

28. Bohman, S. O., G. Jaremko, A. B. Bohlin, and U. Berg. 1984. Foot process fusion and glomerular filtration rate in minimal change nephrotic syndrome. Kidney Int. 25:696-700.

29. Ellis, E. N., M. W. Steffes, B. Chavers, and S. M. Mauer. 1987. Observations of glomerular epithelial cell structure in patients with type I diabetes mellitus. Kidney Int. 32:736-741.

30. Hostetter, T. H., J. L. Olson, H. G. Rennke, and M. A. Venkatachalam. 1981. Hyperfiltration in remnant nephrons: a potentially adverse response to renal ablation. Am. J. Physiol. 25:F85-F93.

31. Olson, J. L., T. H. Hostetter, H. G. Rennke, B. M. Brenner, and M. A. Venkatachalam. 1982. Altered glomerular permselectivity and progressive sclerosis following extreme ablation of renal mass. Kidney Int. 22:112-126. 